\title{
ПРЕПОДАВАНИЕ ИНЖЕНЕРНОЙ ГРАФИКИ В ВУЗЕ
}

\section{TEACHING ENGINEERING GRAPHICS AT THE UNIVERSITY}

N. Anisimova

Summary: The article deals with aspects of the modern system of teaching engineering graphics in higher school. The author outlined the relevance and significance of the topic of the study. A review of studies on the effectiveness of application of software solutions in engineering schedule training has been carried out. It is proposed to consider BIMtechnologies as promising educational modus, arguments are given. The prerequisites for the application of the Moodle educational platform to integrate the new course have been formulated.

Keywords: engineering graphics, design geometry, BIM-technologies, distance learning, Moodle, competence, profession of the future.

\author{
Анисимова Нина Анатольевна \\ к.т.н., доцент \\ ФГБОУВО «Волжский государственный университет \\ водного транспорта» (Нижний Новгород) \\ nina72a@gmail.com
}

Аннотация: Статья посвящена аспектам современной системы преподавания инженерной графики в высшей школе. Автором обозначена актуальность и значимость темы исследования. Проведен обзор исследований по проблеме эффективности применения программных решений в обучении инженерной графике. Предложено рассматривать ВІМ-технологии как перспективный образовательный модус, приведены аргументы. Сформулированы предпосылки для применения образовательной платформы Moodle в целях интеграции нового курса.

Ключевые слова: инженерная графика, начертательная геометрия, ВIMтехнологии, дистанционное обучение, Moodle, компетенция, профессия будущего.

тезис подкрепляется как минимум двумя аргументами. Первый - это невозможность или неспособность образовательных организаций средней ступени подготовить «подготовленного» выпускника. Так, в 2019-2020 гг. в одном из ВУЗов Новосибирска прошло масштабное исследование (выборка 258 студентов первого курса). В результате опросов было определено, что порядка $50 \%$ студентов-первокурсников не изучали в школе черчение, что доказанно коррелирует с параллельным анкетированием по выявлению характера трудностей обучения в техническом ВУЗе (помимо низкой школьной подготовки были определены неразвитость воображения, сложность дидактического материала и высокая интенсивность курса, соответственно) [20, с. 247]. Здесь стоит согласиться с мнением известно исследователя К.А. Вольхина о том, что в высшей школе важно обеспечить «формирование условий, максимально удовлетворяющих индивидуальные потребности каждого студента» $[3$, c. 24].

Достижению данной цели способствует подбор программного инструментария; преобладание теории, выбор неэффективного с методологической точки зрения и (или) неактуального для производственной сферы программного продукта будет являться демотивирующим фактором (второй аргумент). Так, Н.Е. Суфляева в своих публикациях приводит данные о том, что в группах, где инженерно-графические дисциплины изучаются с применением CAD-систем, в значительной степени повышен интерес обучающихся к предметам, лучше успеваемость и уровень стремления студентов к самостоятельному расширению знаний в будущей профессиональной области $[18$, с. 28]. Однако, цифровой мир не стоит на месте: сперва субъектами рынка активно при- 
менялись 2D система, затем экспертным сообществом начала осознаваться важность 3D-методов при решении графических задач, равно как и значимость формирования компетенций, связанных с овладением более современным инструментарием, способным на 4D-, 5D-, 6D- и так далее моделирование. Речь идет о BIM-технологиях.

ВІМ представляет собой информационную модель (моделирование) зданий и сооружений. В более узком смысле, ВІМ - это цифровое представление физических и функциональных характеристик объекта, которое охватывает более чем просто геометрию проектируемого объекта. ВІМ учитывает множество факторов и информацию об объекте, отдельных его элементах (даже деталей производителей), географии, дизайне и других данных, в том числе влияние его на окружающую среду и наоборот. Все эти данные наряду с технико-экономическими показателями и другими характеристиками объекта формируют такую информационную модель, в которой изменение одного параметра приводит к автоматическому перерасчету всех остальных. Информационная модель в данном случае представляет собой «все имеющиеся цифровые характеристики и оптимальным образом организованная и управляемая информация об объекте, используемая как на стадии проектирования и создания объекта, так и в период его эксплуатации и утилизации» [7].

В основе технологии информационного моделирования лежит создание цифровой модели проектируемого объекта, включающей, как правило, трехмерное графическое представление объекта (виртуальную цифровую копию) со всей его начинкой, а также хорошо структурированное цифровое описание его количественных, геометрических и технологических характеристик (параметров и свойств) в целом и входящих в его состав частей (материалов, конструкций, узлов, деталей, изделий, оборудования). Причем все данные не просто собираются воедино (например, в виде некой таблицы или справочника), а связываются между собой программными алгоритмами [10]. Любая корректировка таких данных с учетом заданных зависимостей между ними влечет за собой автоматическое изменение всей модели. Этими свойствами и обеспечивается возможность автоматизированного моделирования различных взаимосвязанных бизнес-процессов [9]. Например, внося изменения в конструктивные или иные проектные решения, пользователь технологии получает возможность не только рассчитать стоимость проектирования, но и спрогнозировать затраты на будущую эксплуатации в заданном отрезке времени, и даже затраты на его снос [23].

Как справедливо отмечает А.В. Гинзбург, программное обеспечение ВIM обладает разнообразным функционалом, состав которого зависит от поставленных задач, стадии жизненного цикла проектируемого объекта, его назначения [4]. В общем случае функционал программного обеспечения ВIM охватывает решение таких задач, как $[1,2,5]$ : (1) разработка и ведение документации в отношении проектируемого объекта, предусмотренной профильным законодательством (обоснование инвестиций, задание на проектирование, проектная документация, исполнительная документация и пр.), (2) контроль соответствия разработанных документов требованиям законодательства РФ и нормативных технических документов, которые подлежат алгоритмизации, (3) расчет, состыковка и согласование компонентов и систем проектируемого объекта, выявление нестыковок (коллизий) в проекте, (4) предсказание эксплуатационных качеств, проверка жизнеспособности и функциональной пригодности будущего объекта, (5) моделирование и анализ влияния проектируемого объекта на окружающую среду, (6) управление эксплуатацией проектируемого объекта, средств технического оснащения в течение всего периода его существования, (7) проектирование и управление реконструкцией, модернизацией и пр. проектируемого объекта и пр.

В целом, подобный функционал ВІМ позволяет качественно снизить объем ошибок при разработке проектной документации, сократить сроки на разработку и внесение оперативны изменений в проектную документацию, повысить эффективность работы проектных организации и, как результат, оптимизировать затраты на проектирование объектов.

Становится очевидным тот факт, что по мере технологического развития общества программное обеспечение ВІМ будет совершенствоваться в стремлении удовлетворить все более широкие потребности участников рынка, в т.ч. будет решать дополнительные задачи. Следовательно, в условиях ухода «на задний план» CAD и CAПР решений, высшей школе необходимо переориентирование вектора компетентностной парадигмы в целях, как уже говорилось ранее, подготовки специалиста, способного к прогнозированию и адаптации к научно-техническому прогрессу. Однако, мы склонны согласиться с позицией М.Г. Тена, С.В. Максимова и И.В. Субботина и других современных ученых, о том, что обучение инженерной графике должно происходить по принципу «от простого к сложному», иными словами без исключения базового инструментария, но с введением практики работы с ВІМ-технологиями с первого курса [20, с. 247]. Помимо всего прочего, это позволит активизировать эмоциональный и волевой компоненты интереса, т.е. студент вне зависимости от уровня владения знаниями, умениями и навыками в области инженерной графики, будет эффективно воспринимать материал и по экспоненте формировать и развивать требуемую компетенцию $[12,15,17]$.

В публикациях Л.А. Голдобиной [6], Ю.А. Лежнина [13], 
А.А. Семенова [16] и др. описывается опыт интеграции ВІМ-технологий в образовательных процесс технических ВУЗов и предлагаются, в частности, междисциплинарные формы изучения, а также проектное комплексное обучение с привлечением студентов различных специальностей. Однако, как комментирует этот момент М.В. Тарасов, в подобной практике имеют место определенные сложности в администрировании учебного процесса при привлечении студентов разных направлений подготовки [19]. Исходя из этого, на начальном этапе важна качественная проработка программы обучения BIM-технологиям студентов конкретных направлений с учетом специфики работы. В этой связи, существует необходимость методологической разработки (методологического решения) в целях «запуска» процесса освоения студентами технических ВУЗов ВІМ-технологий для усовершенствования своих знаний, умений и опыта в области инженерной графики и иных смежных дисциплин, прямо или косвенно пересекающихся с будущей профессией обучающихся.

Одним из вариантов такого методологического решения может стать создание пробного курса обучения с лекциями (теория), семинарами (теория и методология) и онлайн-практическими материалами (методология и практика) на популярной платформе Moodle. Данная система обеспечивает дистанционное взаимодействие и позволяет размещать учебный контент различного содержания. А.А. Темербекова комментирует, что Moodle «дает для преподавания обширный инструментарий для предоставления учебно-методических материалов курса, проведения теоретических и практических занятий, организации учебной деятельности студентов как индивидуальной, так и групповой» [11]. Пользуясь этой системой, студенты могут высылать лабораторные работы, контрольные работы, практические задания (кейсы) по инженерной графике для проверки, проходит онлайн тестирование в целях выявления уровня усвоения учебного материала, задавать вопросы преподавателю. Помимо очевидных достоинств интеграции такого решения, следует назвать (1) расширение образовательных возможностей ВУЗа, (2) сокращение аудиторной нагрузки, повышение гибкости планирования образовательного процесса и мотивации студентов к самообучению, (3) популяризация отечественных образовательных программных разработок, (4) расширение практики применения независимого контроля знаний обучающихся, (5) совершенствование качества обучения и обновление содержания образовательных программ посредством использования онлайн курсов ведущих преподавателей и экспертов и пр. [21, с. 117-118]. В данном случае следует добавить, что преподаватель должен не только обладать информационно-педагогической компетенцией, но и знаниями в области информационного моделирования (BIM) в целях обеспечения эффективной демонстрации на междисциплинарном уровне особенностей примене- ния технологий в решении конкретных задач в области проектирования.

В качестве программного решения для практики обучения студентов инженерной графики с интеграцией основ ВІМ можно рассматривать систему трехмерного проектирования КОМПАС-3D v18. Ключевой особенностью продукта является использование собственного математического ядра C3D и параметрических технологий, разработанных специалистами АСКОН. Сегодня данный программный комплекс является наиболее распространенным, доступным (есть бесплатная версия, которая подойдет для обучения), а также универсальным, так как позволяет разрабатывать в единой среде любые проектные решения. В КОМПАС-3D v18 можно создать скоординированную трехмерную модель проектируемого объекта, элементы модели являются взаимосвязанными и содержат в себе широкий спектр параметров. В целом, такой простой и доступный программный продукт позволит обучающимся быстро понять основы работы с BIM, что доказывает пусть незначительный, но весьма успешный опыт ФГБОУВО «Волжский государственный университет водного транспорта» (г. Нижний Новгород). Более того, в сети есть множество обучающих видео, например, А. Высоцкого (Vysotskiy Consulting - ВIM), который оказал значительное влияние на интеграцию ВІМтехнологий и уже практически десятилетие проводит онлайн и оффлайн обучение сотрудников коммерческих предприятий и студентов СПбГУ.

В заключении отметим, что в условиях проектирования доступной, эффективно сформулированной и оптимально (методически и методологически) обеспеченной образовательной среды, механизмы преподавания инженерной графики в технической ВУЗе будут результативными и соответствующими требованиям времени. В результате прохождения курса, например, «ВІМ-технологии» в рамках программы «Инженерная графика», студенты смогут сформировать следующие общепрофессиональные компетенции выпускника: ОПК-1 - способность решать стандартные задачи профессиональной деятельности на основе информационной и библиографической культуры с применением информационно-коммуникационных технологий с учетом основных требований информационной безопасности и компетенции, ОПК-2 - способность вести обработку, анализ и представление информации в профессиональной деятельности с использованием информационных и компьютерных технологий, ОПК-б - способность участвовать в проектирование объектов строительства и жилищно-коммунального строительства, в подготовке расчетного и технико-экономического обоснования проектов, участвовать в подготовке проектной документации, в т.ч. с использованием средств автоматизированного проектирования и вычислительных программных комплексов и пр. 


\section{ЛИТЕРАТУРА}

1. Абакумов Р.Г., Наумов А.Е., Зобова А.Г. Преимущества, инструменты и эффективность внедрения технологий информационного моделирования в строительстве // Вестник БГТУ им. В.Г. Шухова. 2017. № 5. С. 171- 181.

2. Бачурина С.С, Голосова Т.С. Этапы эффективного внедрения ВІМ в проектной компании // Современные проблемы управления проектами в инвестиционно-строительной сфере и природопользовании: материалы VI-ой междун. науч.-практ. конференции, 15 апр. 2016; Под ред. В. И. Ресина. - М.: ФГБОУ ВПО «РЭУ им. Г. В. Плеханова», 2016. - С. 110-114.

3. Вольхин К.А., Астахова Т.А. Проблемы графической подготовки студентов технического университета. Геометрия и графика. 2014. № 3. С. 24-28.

4. Гинзбург А.В. ВІМ-технологии на протяжении жизненного цикла строительного объекта // Информационные ресурсы России. 2016. № 5 (153). С. 28-31.

5. Гинзбург А.В., Семернин Д.А., Кисель Т.Н. Оценка применения ВІМ-технологий в строительстве: Отчёт о работе по договору 32-С/02-16 от 10 февр. 2016 г. - М.: Институт экономики, управления и информационных систем в строительстве и недвижимости (ИЭУИС), 2016. - 51 с.

6. Голдобина Л.А. Опыт внедрения ВІМ-технологий при подготовке бакалавров по направлению 08.03 .01 «Строительство» // ВIМ-моделирование в задачах строительства и архитектуры: материалы Всерос. науч.-практ. конф. 2018. С. 217-222.

7. Голосова Т.С. Организационно-экономические механизмы перехода на информационное моделирование в архитектурно-проектной деятельности: дисс. ... канд. эконом. наук: 08.00.05. - М., 2018. 156 с.

8. Гузненков В.Н., Журбенко П.А., Винцулина Е.В. Методика преподавания инженерной графики в МГтУ им. Н.Э. Баумана // Международный журнал экспериментального образования. 2019. №2. С. 5-9.

9. Добрынин А.П. и др. Цифровая экономика - различные пути к эффективному применению технологий (BIM, PLM, CAD, IOT, Smart City, BIG DATA и другие) // International Journal of Open Information Technologies. 2016. 4. №. 1. С. 4-11.

10. Ильина 0.Н. Управление проектами по созданию киберфизических систем: внедрение ВIM // Российский журнал управления проектами. - 2017. Т. 6. № 4. C. $44-49$

11. Информация и образование: границы коммуникаций INF0'16: сборник научных трудов № 8 (16) / под ред. А.А. Темербековой, Л.А. Альковой. - ГорноАлтайск: РИО ГАГУ, 2016. - 258 с.

12. Князева 0.Г. Профессиональная направленность обучения математике в технических вузах // Известия АлтГУ. 2012. №2-1. С. 17-21

13. Лежнина Ю.А. Разработка модуля «Информационное моделирование зданий» на основе компетентностного подхода // Известия КГАСУ. 2017. № 2 (40). С. 322-330.

14. Макаренко Г. 100 профессий будущего. - 19.12.2019 // РБК. Экономика образования. - ULR: https://www.rbc.ru/trends/education/5d6e48529a7947777002 $717 b$ (дата обращения: 20.03.2020)

15. Макарова Е.А., Федькина Л.И. Эмоционально-волевой компонент образовательного процесса // Вестник Таганрогского института имени А.П. Чехова. 2017. №1. С. 65-69.

16. Семенов А.А. Интеграция концепции ВІМ в учебный процесс строительных вузов // ВІМ-моделирование в задачах строительства и архитектуры: материалы Всерос. науч.-практ. конф., 2018. С. 207-211.

17. Сергеева И.А., Петухова А.В. Инженерно-графическая подготовка студентов в условиях компьютеризации обучения // Вестник евразийской науки. 2014. №3 (22). $11 \mathrm{c}$.

18. Суфляева Н.Е. Современные аспекты преподавания графических дисциплин в технических вузах. Геометрия и графика. 2015. Т. 2. № 4. С. $28-33$.

19. Тарасов М.В. Изучение технологий информационного моделирования зданий в образовательном процессе бакалавров по направлению «строительство» // Вестник ЮУрГУ. Серия: Образование. Педагогические науки. 2019. №1. С. 87-97.

20. Тен М.Г., Максимова С.В., Субботина И.В. Инновационные подходы к формированию профессиональных компетенций студентов технического ВУЗа в условиях модернизации профессионального образования // МНК0. 2020. №1 (80). С. 246-249.

21. Тимофеев В.Н., Демина Ю.Ю. Развитие методики преподавания инженерно-графических дисциплин в техническом ВУЗе // Международный журнал гуманитарных и естественных наук. 2020. №2-1. С. 116-119. С. 117

22. Фиговский О. Инженер - профессия будущего. - 10.05.2011 // Научно-образовательный портал IQ (НИУ ВШЭ). - ULR: https://iq.hse.ru/news/177672636. html (дата обращения: 20.03.2020)

23. Smith D. An Introduction to Building Information Modeling (BIM) // Journal of Building Information Modeling. 2007. pp. 12-14

(c) Недорубов Андрей Николаевич (batrakan@rambler.ru). 